RESEARCH ARTICLE

\title{
Principles of public internal controls: A mediation role of information and communication
}

\author{
Peter Yao Lartey ${ }^{1^{*}}$ Santosh Rupa Jaladi $^{2}$ Stephen Owusu Afriyie $^{3}$ Isaac Gumah Akolgo ${ }^{4}$ \\ ${ }^{1}$ School of Accounting, Universidade Federal de Uberlndia, Uberlndia, MG, Brazil \\ ${ }^{2}$ Prin. L.N Welingkar Institute of Management Development \& Research, Bangalore 560100, India \\ ${ }^{3}$ IT Business, Ghana Communication Technology University, PMB 100, Accra North, Ghana \\ ${ }^{4}$ Department of Marketing and entrepreneurship, SD Dombo University of Business and Integrated Development Studies, Ghana
}

\section{Check for updates}

Correspondence to: Peter Yao Lartey, School of Accounting, Universidade Federal de Uberlndia, UberIndia, MG, Brazil; E-mail: efopeter@yahoo.com

Received: January 3, 2022;

Accepted: February 8, 2022;

Published: February 11, 2022.

Citation: Lartey PY, Jaladi SR, Afriyie SO, et al. Principles of public internal controls: A mediation role of information and communication. Front Manage Bus, 2022, 3(1): 149-166

https://doi.org/10.25082/FMB.2022.01.002

Copyright: () 2022 Peter Yao Lartey et al. This is an open access article distributed under the terms of the Creative Commons Attribution License, which permits unrestricted use, distribution, and reproduction in any medium, provided the original author and source are credited.

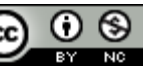

\begin{abstract}
While empirical research has demonstrated the critical nature of internal controls, there is insufficient evidence to indicate that they are effective at detecting and preventing irregularities in the public sector. By analyzing the direct and indirect relationships between internal control components, this study focuses on the quality of internal control in Ghana's public sector. In order to determine whether ongoing controls are consistent with sound public policy, a survey was designed and distributed to public sector employees and managers. According to the evidence, public administrators require high-quality information and communication tools to supplement their existing control systems. Additionally, internal controls are significantly influenced by risk assessment and the control environment, whereas monitoring and control activities have a limited impact. Effective internal communication is necessary for the coordination and implementation of control policies.
\end{abstract}

Keywords: internal controls, public sector, information and communication

\section{Introduction}

Internal controls are often the driving force behind sound public governance that seeks to protect the interests of large stakeholders. This contributes to the public sector's transparent and accountable governance, as well as responsible financial management and administration [1]. Internal controls are necessary at all stages of continuous management activities, including providing important services to the public, disbursement, allocation, and redistribution of economic resources [2]. Additionally, internal control is essential to assess or score the performance of public institutions in light of their unique goals, objectives, and anticipated outcomes. Internal control is required for the public sector to operate effectively and to be led by legal frameworks, high ethical standards, and to promote compliance with all applicable domestic and internal rules governing public administration [3]. Internal control practices are examined and certified by the auditor general in Ghana's institutional setting, while the public accounts committee of parliament conducts a holistic assessment of the public sector on the basis of accountability [4]. Verification areas include budget allocations and public expenditure appropriations in compliance with numerous laws, including the procurement act. These procedures will encourage appropriate spending, accounting, and management system reporting and measurement. Effective internal controls have shown that indicators are accessible to all stakeholders, including citizens, to guide their value for money assessments. Internal control principles now in use include: INTOSAI [5], COSO [6] and OECD [7] guidelines among others. In public institutions, the standards embedded in these principles give reasonable confidence and guarantee the achievement of strategic, operational, compliance, and reporting objectives. Control environment, control activities, risk assessment, monitoring, communication, and information prescribed in the internal control mechanism are the most extensively used internal control mechanisms COSO [8] COSO [9] and COSO [10].

COSO contains seventeen integrated concepts developed from the original framework COSO [6]. Internal control effectiveness provides governments and policymakers in the public sector with a comprehensive assurance based on high objectivity and operational efficiency. The purpose of this study is to investigate the factors that influence the efficiency of internal controls 
in a Ghanaian public institutional setting. Additionally, because control effectiveness may not be uniform throughout, efficiency must be evaluated periodically in a continuous process throughout time. Internal controls relate to the policies and processes developed and followed by an entity's board of directors and management to enhance operational efficiency, financial reporting, compliance objectives, and the expectations of key stakeholders regarding asset and investment protection Commission [11] defines internal control as a continual method of reviewing an entity, however this technique must be examined, assessed, and subject to consistency to reduce risk to a minimum. Additionally, internal control may be successful this year but may not be effective the following year. Apart from that, new risks are arising in along with increasing public sector obligations.

\section{Internal control effectiveness}

Internal control effectiveness is measured in a variety of ways depending on how closely internal policies adhere to the following objectives: (1) operational efficiency, (2) financial reporting reliability, (3) compliance with applicable laws and regulatory standards, and (4) compliance with various constitutional provisions governing public institutions [12]. In a majority of cases, depending on the context, the internal control objectives serve as the yardstick for monitoring effectiveness. Chang, Chen [13] argue that effective internal control measures require increased fraud detection and prevention. Similarly, Kong, Lartey [14] assert that internal control mechanisms are effective when existing and emerging organizational risks are mitigated and addressed appropriately to reduce the impact of risk on profit and investment Internal control efficacy, according to OECD [7], translates into strong governance; it must ensure transparency in all accounting and financial operations. Those in charge of public resources and institutional governance adhere to a high ethical code of conduct. Internal control is a critical component of corporate governance, and its success in the public sector is critical. According to Udeh [15], internal control efficacy ensures the prudent use and protection of public sector assets. Effective controls ensure that asset records and inventory are kept current in daily operations. Effective controls are largely dependent on adherence to constitutional and regulatory provisions Pakurr, Haddad [16]. Additional signs of effective control include the degree to which the internal audit is designed to be independent in order to protect the integrity of the regulatory regime and the daily validation of transactions [17]. Alternatively, Lartey, Kong, Afriyie, Santosh, and Bah (2020) examined the board's independent oversight and also viewed the audit committee's objectivity in tightening control policies with the assistance of external auditors responsible for validating accountability standards as part of essential indicators of internal control effectiveness. According to COSO, (1992), every member of an organization, whether public or private, is accountable for internal controls. To have effective internal controls, the organization's leadership must demonstrate a commitment to integrity and ethical standards.

Hanggraeni, lusarczyk [18], hold management responsible for implementing key strategic policies and controls developed by the board in order to maintain performance against standard procedures. When employees consistently provide feedback through internal communication, it is more effective. The entire operation is based on a one-of-a-kind control mechanism that directs management activities such as people and resource management in accordance with long-term goals.

The board's role is critical in achieving the public sector's primary goals, which include accounting for public resources, reporting and compliance, providing essential services, and following best international accounting practices. The board's role is defined as "a deliberate effort by the board and management to design policies that will align the organization's activities with its strategic objectives" in the definition of internal controls [10] According to this definition, the board of directors plays a critical role in improving the effectiveness of controls at the board level by strengthening the characteristics that represent good corporate practices and behavior, demonstrating their commitment to the control policies that they introduce at the board level (COSO, 2013). Both private and public organizations have similar board characteristics, which are frequently examined to determine whether the board is reactive or proactive in assessing existing controls. Furthermore, "supervision" is used to illustrate the link between good governance and internal control. Internal controls also refers to internal supervision, whereas good governance refers to effective supervision and control.

\subsection{Hypotheses development}

To investigate direct and mediation effects, the researcher devised specific hypotheses. The rating criteria and definitions of internal control indicators used in the study are presented 
in Table 1. The mediation between the constructs is depicted in Figure 1, implying that the statistical analysis will produce direct relationships or, alternatively, the mediation impact. Figure 1 also depicts information and communication acting as a mediator in accordance with COSO [8] and COSO [6], which emphasizes that communication is the only component responsible for connecting all of the components for proper functioning.

Control environment, risk assessment, control activities, and control effectiveness all interact through information and communication. The study investigates whether the effectiveness of internal controls is improved when communication channels are improved.

Table 1 Internal Control (I.C) dimension Criteria (Index) and rating

\begin{tabular}{|c|c|c|}
\hline Internal Control (I.C) Dimension - Criteria & Rating $(5-1)^{*}$ & Definitions of critical controls ratings for the questionnaire (Rankings) \\
\hline Adequacy of Sound Control & 5 & $\begin{array}{l}\text { Controls aligned with objectives } \\
\text { Controls aligned with risk } \\
\text { Controls aligned with monitoring } \\
\text { Consistency with material Disclosures over time }\end{array}$ \\
\hline Adequacy of Controls with areas of improvement & 4 & $\begin{array}{l}\text { Controls Inclined Leadership based on Board \& Management commitment } \\
\text { Evidence of existing Policies aligning the organization towards Compliance } \\
\text { Evidence of Controls Activities and Practices in the areas of resource, } \\
\text {-information \& safeguarding assets }\end{array}$ \\
\hline General adequate control with critical areas & 3 & $\begin{array}{l}\text { Financial Reporting and Track Record in Transparency } \\
\text { Evidence of ethical practices at Department/Unit handling accounting and- } \\
\text {-auditing related matters } \\
\text { Controls for internal audit independence } \\
\text { Evidence of board commitment to internal controls } \\
\text { Evidence of good governance } \\
\text { Evidence of segregation of duties }\end{array}$ \\
\hline Inadequate controls subject to significant improvements & 2 & $\begin{array}{l}\text { IT infrastructure supporting internal controls } \\
\text { Independence of the audit committee }\end{array}$ \\
\hline Insufficient / weak controls & $1 / 0$ & Combination of the wrong types of controls \\
\hline
\end{tabular}

Note: * 5: Strong; 1: Weak

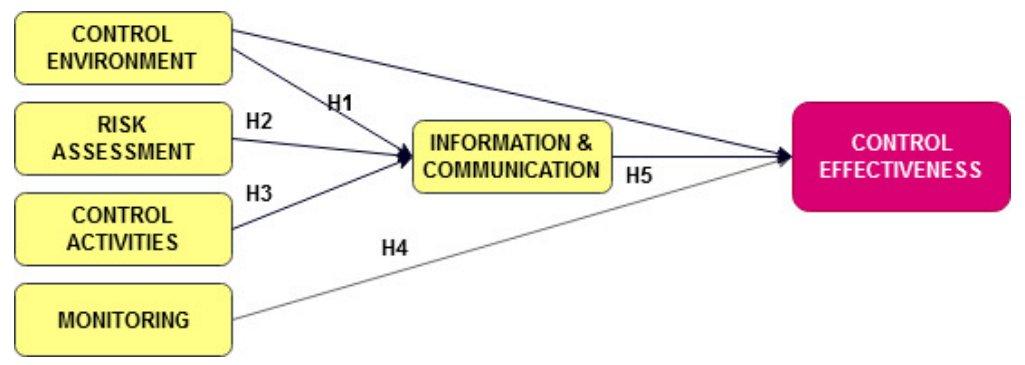

Figure 1 Conceptual framework

\subsubsection{Control environment}

The control environment is a critical component of internal controls. According to Liu [19], the foundation of all internal controls principles is organizational philosophy, tone at the top, integrity, core values, and embedded ethical standards. Creating an ethical environment requires management and board commitment [18]. Ferry [20] defines control environment as an intangible structure that defines the organization's culture and philosophy. Internal control principles must be embedded in people's minds and visible in their behavior, culture, and core values if they are to be followed. Trust, integrity, standards, implicit attitude, moral and ethical climate are all pillars of this philosophy. The COSO commission calls the tone at the top [8]. The reason is that the board's attitude determines the effectiveness of control, as proven and investigated. Gurd and Helliar [21], concluded that leadership and commitment to ethical practices lay the groundwork for other controls. According to Organ [22], shared values define people's behavior and are a mechanism that regulates attitudes toward transparency and ethical business practices. The direct and indirect effects of control environment on internal control effectiveness are examined. Managerial policies generally represent the control environment [23]. The study proposes hypotheses to assess the variable's direct and indirect effects on effectiveness. 
Hypothesis 1a: control environment positively enhances effective internal controls

Hypotheses $1 \boldsymbol{b}$ : the relationship between control environment and effective control is mediated by information and communication

\subsubsection{Risk assessment}

Internal control is responsible for identifying potential threats to the strategic objectives [12]. Internal control principles are intended to maintain best practices and reduce risk. This internal control component helps the organization identify obstacles to achieving its stated goals. Risk assessment measures performance against standards, identifies deviations, and lists all threats and opportunities facing the organization [24]. This step precedes control activities. Risk assessment is a team effort between the audit committee, external auditors, and internal auditors [25]. Because every business is exposed to some level of risk, there must be a way to assess, identify, and manage it [26]. External auditors, in consultation with audit committees, must develop a risk management program to identify and manage risk. It should include processes such as record keeping review and validation, accounting reporting, asset valuation and verification, and general performance assessment, according to Kong, Lartey [14] According to Lawson, Muriel [27], management's understanding of business risk influences their choice of internal control mechanisms.

Hypothesis 2a: risk assessment positively enhances internal controls

Hypothesis $2 \boldsymbol{b}$ : the impact of risk assessment on effective control is mediated by information and communication

\subsubsection{Control activities}

Traditionally, control activities are the policies that management uses to resolve any type of organizational risk [10]. The process may be deficient if there is a breakdown in communication between management employees and the organization's director. In the majority of empirical studies, control activities are defined as the response strategy to adverse events that result in the failure of internal controls [28]. The majority of control activities that have been quantified and shown to improve internal control include job segregation, approval, employee rotation, and reconciliation of accounting and financial records [29]. Given that management relies on internal communication's effectiveness to enforce internal control policies, the researcher intends to quantify the mediation effect that control activities have on internal control effectiveness when information and communication are used as mediators.

Hypothesis 3a: control activities has a positive impact on internal controls in public sector

Hypothesis $\mathbf{3 b}$ : the impact of control activities on effectiveness is enhanced by information and communication

\subsubsection{Monitoring}

According to COSO [10] internal control effectiveness can only be ascertained after consistent evaluation over time. Aside from the strategic goals, compliance goals ensure that all actions are within the bounds of all applicable laws and regulations, as well as internal policies [?]. They set new goals every year. Achieving these goals requires constant revision of control policies and strategies. This will help management identify strategy changes and deviations [31]. External auditors help identify and evaluate poor performance. To identify fraudulent transactions, errors, misappropriation, non-transparent and transactions that may be inconsistent with best practices. Every day, internal auditors assess internal control practices for compliance and deviations from standards. According to Zarychta, Grillos [1] monitoring is required as new risks emerge as operations and responsibilities expand. If existing controls fail, management may take corrective action and address the risk with appropriate policies [27]. In this study, the effectiveness of monitoring and control is measured as follows:

Hypothesis4: monitoring significantly enhances control effectiveness

\subsubsection{Information and communication}

Internal controls are based on information and communication. This principle establishes a link or connection between the internal control components in order to maximize their effectiveness. Internal control elements are not interdependent on each other, according to Chen, Yang [32], This necessitates the maintenance of high-quality internal communication channels to aid in the rapid detection of potential flaws. Management relies on information and communication to convey instructions for every policy of internal control, such as physical controls, segregation of duties, performance supervision, compliance controls, arithmetic and accounting controls, auditing and review processes. Management's response to fraud, irregularities, and 
errors is delayed due to ineffective communication [33]. This component is critical in ensuring that controls functions keep the organization on track to meet its strategic goals. To disseminate policies established by the board to every unit and department within an organization, better channels of information and communication are required [34]. To facilitate the audit committee's and external auditors' work on risk and internal control policies, communication is required. That aligns with the viewpoints of Johanson [35], who claims that when the risk assessment and monitoring process identifies any internal deficiencies, management is able to prepare in terms of finances and resources to respond appropriately. As a result, based on several empirical researchers' opinions, this study assesses the impact of information and communication, concluding that:

Hypothesis 5: information and communication significantly enhances internal control effectiveness

\section{Methods}

A Likert scale was used to assess relevant multi-item questions. The questions were scaled from 1 to 5 , with 1 denoting "strongly disagree" and 5 denoting "strongly agree" [36]. It is very convenient to distribute questions to 500 public servants from public organizations, in Ghana with 450 valid responses received and analyzed. There is limited empirical research using Ghana's public sector as a unit of study, which influenced the feedback rate of 450 completed questionnaires. To perform a partial least-square and confirmatory factor analysis, smart-PLS and Amos statistical tools were used. The theoretical framework outlines the study's structure and variables to be investigated. Risk Assessment (RSK), Control Activities (CAT), Control Environment (CENT), Monitoring (MNT), Informational and Communication are the independent variables (IFC). Internal Controls Effectiveness will be predicted using these constructs $(\mathrm{EFF})$. Table 2 lists the measurement items for each construct.

Table 2 Questionnaire items of observable/explicit variables

\begin{tabular}{|c|c|}
\hline Latent/Implicit variables & Observable/Explicit variables \\
\hline Control Environment & $\begin{array}{l}\text { (CENT1) The board and management demonstrate commitment to integrity and ethical standards } \\
\text { (CENT2) The culture and philosophy of management and the board is based on principles of internal controls } \\
\text { (CENT3) The board of directors demonstrate sufficient independence } \\
\text { (CENT4) The board and management have established clear oversight structures for reporting, approval, feedback and authority }\end{array}$ \\
\hline Risk Assessment & $\begin{array}{l}\text { (RSK1) There are clearly stated objectives for identifying and assessing risks } \\
\text { (RSK2) The organization considers fraud and irregularities as risks } \\
\text { (RSK3) There are risk policies that identifies changes and weaknesses in the existing internal controls } \\
\text { (RSK4) Risk programs are aligned with internal control principles }\end{array}$ \\
\hline Monitoring & $\begin{array}{l}\text { (MNT1) Assessing internal controls is a continuous process } \\
\text { (MNT2) Evaluation of internal control effectiveness is done by independent parties } \\
\text { (MNT3) The board and management is committed to voluntary disclosure of material information during audit } \\
\text { (MNT4) Monitoring is based on review of performance against standards }\end{array}$ \\
\hline Control Activities & $\begin{array}{l}\text { (CAT1) The organization develops tools and policies to respond to risks } \\
\text { (CAT2) The control activities are adequate enough to address all manner of risks } \\
\text { (CAT3) Control activities are supported by adequate technology tools and infrastructure } \\
\text { (CAT4) Controls activities include segregation of duties }\end{array}$ \\
\hline $\begin{array}{l}\text { Information and } \\
\text { Communication }\end{array}$ & $\begin{array}{l}\text { (IFC1) There is a good linkage between all the components of internal controls } \\
\text { (IFC2) The organization processes information using relevant technology tools } \\
\text { (IFC3) The organization has proper channels of communications supporting internal controls } \\
\text { (IFC4) The communication channels supports quality and timely reporting }\end{array}$ \\
\hline
\end{tabular}

\subsection{The model constructs and measurement procedures}

The variance and covariance of the variables that make up the endogenous, which are modelled as functions of the exogenous constructs, are calculated as follows:

$$
y=\beta y+\Gamma x+\zeta
$$

The above function present the matrix and its parameters. Causal parameters include $\gamma$ and $\beta$. In this case $\gamma$ is representing the parameters and their estimates relating to each exogenous variable. While, $\beta$ also represents the measurement of parameters relating to the endogenous constructs. The $\mathbf{p}$ by $\mathbf{q}$ matrix $\Gamma$ comprises of coefficients of the $\mathbf{y}$ on the $\mathbf{x}$, while the error vector, $\zeta$, is $\mathrm{p}$ by $\mathbf{1}$. 


\section{Empirical results and analysis}

Structural equation modelling (SEM) is best defined as the integration of various multivariate techniques into a single model fitting framework, which includes measurement theory, factor analysis (latent variables), path analysis, regression modelling, simultaneous equations (derived from econometrics), and a variety of other generalized linear models [37]. As shown in Table 2, path analysis is widely used because it considers both direct and indirect effects when explaining the system of relationships between multiple observe variables or questionnaire items.

\subsection{Confirmatory factor analysis}

Structural Equation Modeling (SEM), is a comprehensive method of verifying the validity of latent constructs in a model. The process of validating these constructs is termed as Confirmatory Factor Analysis (CFA). CFA performs unidimensionality test based on construct validity and reliability. Empirical researchers perform the CFA procedure prior to interrelationship modeling using SEM. The CFA technique aims at testing the factor structures to confirm the correlation and significant level of the constructs.

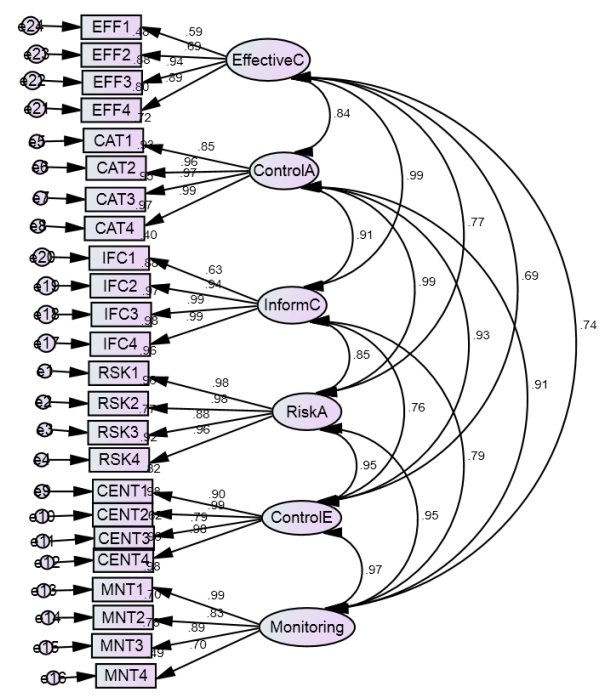

Figure 2 Correlation between latent and observable variables

Figure 2 shows a significant correlation between the constructs, which is supported by higher loadings for each measuring item. Internal control variables have a strong correlation with effectiveness, according to the path results. Control Activities (CAT) and Effectiveness (EFF) have a correlation of $(=0.84)$, while information and communication have a correlation of (=0.99). Furthermore, Risk Assessment $(\mathrm{RSK})$ has a $(=0.77)$ correlation with Effectiveness. Control Environment (CENT) has a $(=0.69)$ correlation with Effectiveness, while Monitoring $(\mathrm{MNT})$ has a $(=0.74)$ correlation with Effectiveness $(\mathrm{EFF})$. Considering the relationship between the results, it can be concluded that internal controls practices in Ghanaian public organizations are very effective, and that standard practices such as ethical values, risk management, and due diligence are being applied satisfactorily. Therefore, the implication is that internal control practices are very effective and efficient and they can be relied upon to formulate management decisions.

Because the variables were not used in isolation, the study found that the interrelationship between all of the constructs is extremely important. This demonstrates how each construct is reliant on the others. Based on the current findings, it can be concluded that the factors influencing the effectiveness of internal controls in public organizations are determinants, and the researcher rejects the null hypotheses in favor of the alternative hypotheses, as stated in the hypotheses.

Additional reports from the Confirmatory Factor Analysis revealed that correlations have significant p-values, standard errors, and estimates (see Table 3). Each of the constructs had a positive $p$ value, indicating that the relationship between the independent variables and the effectiveness of the internal control is highly significant. For instance, risk assessment has a strong correlation with effectiveness, with estimates of risk assessment having a very significant estimate of $($ RSK3 $)=1.492$, indicating that the variable is likely to have a beneficial effect on 
Table 3 Constructs correlation parameters

\begin{tabular}{|c|c|c|c|c|c|c|c|}
\hline \multicolumn{3}{|c|}{ Constructs } & \multirow{2}{*}{$\frac{\text { Estimate }}{10.000}$} & \multirow[t]{2}{*}{ S.E. } & \multirow[t]{2}{*}{ C.R. } & \multirow[t]{2}{*}{$\mathrm{P}$} & \multirow[t]{2}{*}{ Label } \\
\hline RSK1 & $<-$ & RiskA & & & & & \\
\hline RSK2 & $<-$ & RiskA & 1.112 & 0.015 & 72.542 & $* * *$ & par_1 \\
\hline RSK3 & $<-$ & RiskA & 1.492 & 0.044 & 34.200 & $* * *$ & par_2 \\
\hline RSK4 & $<-$ & RiskA & 0.832 & 0.015 & 55.485 & $* * *$ & par_3 \\
\hline CAT1 & $<-$ & ControlA & 10.000 & & & & \\
\hline CAT2 & $<-$ & ControlA & 0.876 & 0.030 & 290.073 & $* * *$ & par_4 \\
\hline CAT3 & $<-$ & ControlA & 0.796 & 0.027 & 29.838 & $* * *$ & par_5 \\
\hline CAT4 & $<-$ & ControlA & 0.884 & 0.029 & 30.764 & $* * *$ & par_6 \\
\hline CENT1 & $<-$ & ControlE & 10.000 & & & & \\
\hline CENT2 & $<-$ & ControlE & 0.945 & 0.024 & 39.750 & $* * *$ & par_7 \\
\hline CENT3 & $<-$ & ControlE & 0.868 & 0.040 & 21.771 & $* * *$ & par_8 \\
\hline CENT4 & $<-$ & ControlE & 0.952 & 0.025 & 38.805 & $* * *$ & par_9 \\
\hline MNT1 & $<-$ & Monitor & 10.000 & & & & \\
\hline MNT2 & $<-$ & Monitor & 10.094 & 0.037 & 29.220 & $* * *$ & par_10 \\
\hline MNT3 & $<-$ & Monitor & 10.069 & 0.030 & 360.070 & $* * *$ & par_11 \\
\hline MNT4 & $<-$ & Monitor & 1.194 & 0.063 & 190.039 & $* * *$ & par_12 \\
\hline IFC4 & $<-$ & InformC & 0.944 & 0.059 & 160.058 & $* * *$ & par_13 \\
\hline IFC3 & $<-$ & InformC & 10.061 & 0.066 & 15.996 & $* * *$ & par_14 \\
\hline IFC2 & $<-$ & InformC & 0.748 & 0.048 & 15.497 & $* * *$ & par_15 \\
\hline IFC1 & $<-$ & InformC & 10.000 & & & & \\
\hline EFF4 & $<-$ & Effective & 10.000 & & & & \\
\hline EFF3 & $<-$ & Effective & 0.945 & 0.028 & 33.435 & $* * *$ & par_16 \\
\hline EFF2 & $<-$ & Effective & 1.333 & 0.077 & 17.282 & $* * *$ & par_17 \\
\hline EFF1 & $<-$ & Effective & 10.000 & & & & \\
\hline
\end{tabular}

internal control effectiveness. Additionally, this value has a reliable S.E. $=0.044$ and a C.R. $=$ 72.542. Both composite reliability and standard errors are positive indicators of significant and reliable relationships. Taking into account the contribution of control activities, (CAT2) $=0.876$, S.E $=0.030$, and C.R $=29.073$, this indicates that the control activities being conducted are highly relevant and achieving the desired results.

\subsection{Partial least squares correlation}

Figure 3 depicts the correlation coefficients that indicate the relationship between the constructs and the factor. Monitoring, control environment, risk assessment, control activities, and information and communication were all observed constructs. These variables are the determinants of the effectiveness of internal control.

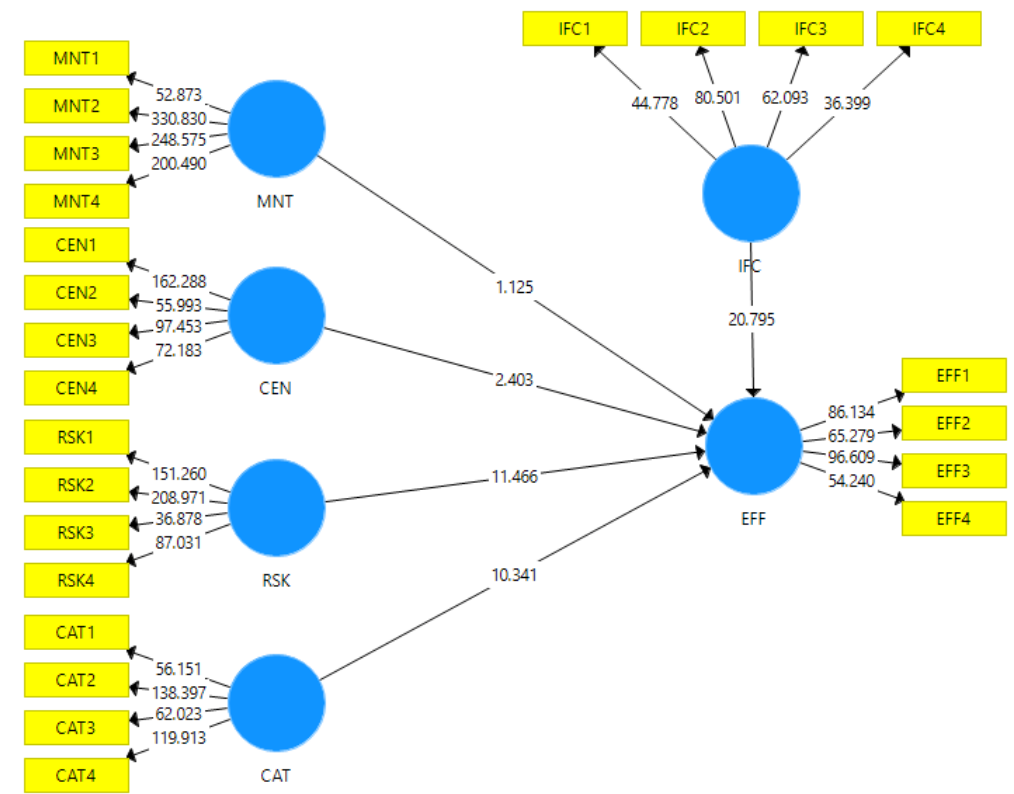

Figure 3 Path analysis of IFC, CAT, RSK, CEN and MNT

The measuring items have exceptionally high values, and each construct has a strong rela- 
tionship with the effectiveness of internal controls. Information and communication (IFC) is equal to 20.795 , monitoring (MNT) is equal to 1.125 , control environment (CENT) is equal to 2.403, risk assessment (RSK) is equal to 11.466 and control activities (CAT) is equal to 10.341. The findings suggest that internal control determinants are effective in public organizations, with information, communication, risk assessment, and control activities being the most effective. The findings also point to a shaky link between monitoring, control environment, and internal control effectiveness. The monitoring and control environment, on the other hand, appears to have a weak and moderate influence on effective internal controls, despite the lack of negative correlations. Based on the influence of the three most significant determinates, it can be said that the internal control system in public organizations is effective on average. When controls are highly visible and are intended to limit or direct an individual's behavior, it means the organization is deploying specific controls to achieve a specific result at a specific time through the use of procedures, planning, allocating specific authority, and supervision to perform a specific task, as previous empirical studies have revealed [32] Internal controls are easily observable and measured, according to the correlation results, which is why traditional internal control effectiveness is only measured using specific international standards without considering any other approach. Internal controls, also known as formal controls, are used by public organizations and are based on the results. Because internal controls are essential for the efficiency and continuity of public organizations, no organization can survive without them [38]. Internal controls do not guarantee that they are adequate to address all types of wrongdoings; they must be reviewed on a regular basis to meet current risks and adopt new methods. That implies that, despite internal controls, the organization and its people may not be immune to excesses. Findings also show that control effectiveness is not permanent, and because it changes over time and should be subjected to continuous evaluation, a good evolution of management processes is required to find a permanent solution to accounting and corporate scandals resulting from internal controls weaknesses, according to Lartey et al. [12].

The discriminant validity result also confirms that each variable has a high level of reliability, which is close to one. Control activity, for example, has a discriminant value of CAT $=0.911$, indicating a high level of prediction reliability. Furthermore, the control environment has a CEN of 0.945 , indicating that making decisions about the control environment is more reliable. Furthermore, the dependent variable, internal control effectiveness, has a very high reliability of $\mathrm{EFF}=0.841$. IFC $=0.943$ is the level of information and communication reliability. Risk assessment and monitoring, on the other hand, have 0.869 and 0.951 , respectively. (see Table 4 )

Table 4 Discriminant validity

\begin{tabular}{lcccccr}
\hline & CAT & CEN & EFF & IFC & MNT & RSK \\
\hline CAT & 0.911 & & & & & \\
CEN & 0.945 & 0.910 & & & & \\
EFF & 0.841 & 0.849 & 0.885 & & & \\
IFC & 0.943 & 0.903 & 0.920 & 0.854 & & \\
MNT & 0.869 & 0.916 & 0.842 & 0.866 & 0.928 & \\
RSK & 0.951 & 0.951 & 0.844 & 0.887 & 0.919 & 0.909 \\
\hline
\end{tabular}

The model evaluation provides empirical evidence as to whether public organizations are more aligned to internal controls and which variables determine whether or not internal controls are effective. The discriminant result indicates that there is a high level of reliability on which to base the relationship between all variables and effective internal controls. By having correlations closer to 1 , all of the variables are more influential, as well as pointing out how the constructs contribute to each other's weight. This explains the model's dependability and confirms the goodness of fit indicators.

\subsection{Path estimation of direct variance}

Figure 4 shows a direct relationship predicted by independent variables. Using the Partial Least Square technique, the relationship between the latent variables and the factor is expressed as a linear function. In the path diagram, it explains the causal assumption of causes and effects.

The causal effect is one-way in the figure, and the error terms or residuals are uncorrelated with the latent variables. When the constructs are measured in scale intervals, the results assume perfect reliability. The model assumes that the latent variables are expressed in a standard z-score as: $\mathbf{z 1}=\mathbf{e 1}$ because the paths regressions are based on correlations. The e denotes stray causes or other non-model factors, not necessarily the error measurement. According to the Rsquared $\left(\mathrm{R}^{2}\right)=0.888$, the variables satisfactorily predict internal control effectiveness. It implies that Ghana's public sector has effective internal controls. As a result, the unexplained 


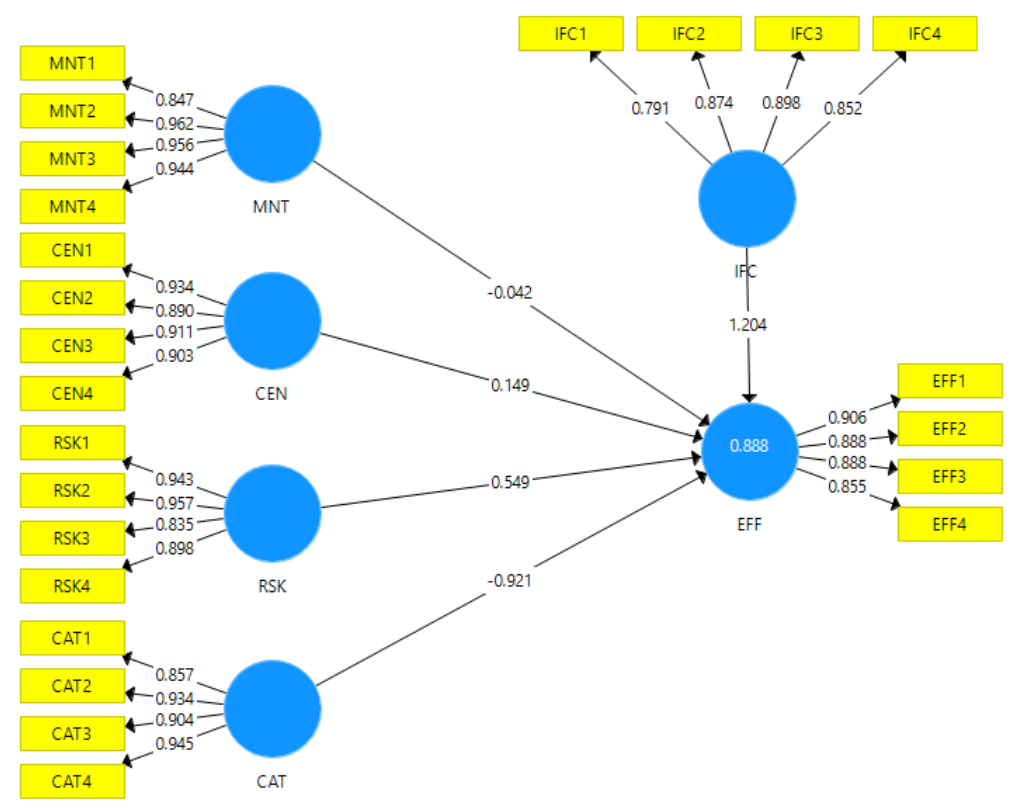

Figure 4 Path prediction and estimates

variance is 11.2 percent. These coefficients represent the independent variables' direct effects on the effectiveness of internal controls. Some variables have negative coefficients, as shown by the arrows directing the causal relations. Information and communication $($ IFC) $=1.204$, control environment $(\mathrm{CEN})=0.149$, and risk assessment $(\mathrm{RSK})=0.549$ are the main determinants of internal control, according to the findings. Monitoring and control activities have a score of -0.042 and -0.921 , respectively. The findings suggest that public organizations rely on three internal control variables the most, while the existing control activities are weak and insufficient to support effective controls. In normal regression terms, these values indicate that improving the control environment, risk management, and internal communication will increase the effectiveness of internal control in a public organization by $1.204,0.149$, and 0.549 , respectively. Because it carries instructions across the organization and the "tone at top," information communication is critical in implementing effective controls. Every element of internal control may cease to function if information and communication fail. The total degree of variance explained in the model is 0.888 . The $\mathrm{R}^{2}$ is the total variance that each latent variable tested in the model contributes [39]. The measurement of the $\mathrm{R}^{2}$ is guided by rules, and it is also known as the in-sample prediction power. As a result, it is critical for policymakers to make decisions based on these values to implement better control policies in the public sector, where large sums of money are spent on financing government services. According to previous scholars, the criteria for measuring explanatory power is between " 0 and 1." [40]. Because a higher variance is closer to 1 , empirical researchers have reported highly significant variance when the $\mathrm{R}^{2}$ is 0.6 or higher, while 0.4 and 0.5 represent a weak or moderate effect in many cases [41]. There are no universally accepted criteria; however, assessment varies across subject areas and is largely dependent on context rather than just the results; this informs researchers' assessments of what constitutes significant, weak, and moderate variance. In the context of firm performance and stock returns, a previous study [42], found $0.12 \mathrm{R}^{2}$ to be satisfactory. Individual latent constructs that contribute to the significant $\mathrm{R}^{2}$ value of 0.888 have a higher $R^{2}$. The researchers consider the $R^{2}$ value to be very significant in this context, looking at the percentage of unexplained value of 0.112 , which is also attributed to model error and other determinants outside the scope of this study. In the absence of collinearity issues, empirical researchers should consider interpreting the $\mathrm{R}^{2}$ in the context of their study area and relating their report to previous studies using similar methods to avoid complexities, according to Hair et al. (2019). Because the partial regression model can be complex, researchers must exercise caution in order to detect an over-fit model for the purposes of $\mathrm{R}^{2}$ prediction reliability similar to Sekaran and Bougie [43]. According to Fornell and Larcker [44], researchers use the $\mathrm{R}^{2}$ value to confirm their inferential judgement on a subject; therefore, when researchers apply models to concepts with predictable indicators in life sciences, biological science, and medical sciences, an $\mathrm{R}^{2}$ of 0.95 is acceptable; however, in social science, where prediction is based on hypothesis, such a high $\mathrm{R}^{2}$ value or more could signal model over-fitting.

Table 5 elaborate on the estimated impact of the independent variables on the internal 
Table 5 Predictions, significance and coefficients

\begin{tabular}{lcccrr}
\hline Path Parameters & Beta & Mean & Std Deviation & t-Statistic & P-value \\
\hline CAT - > EFF & -0.921 & -0.922 & 0.089 & 10.341 & 0.000 \\
IFC - > EFF & 0.149 & 0.157 & 0.062 & 2.403 & 0.016 \\
IFC - > EFF & 1.204 & 1.197 & 0.058 & 20.795 & 0.000 \\
MNT - > EFF & -0.042 & -0.040 & 0.037 & 1.125 & 0.261 \\
RSK - > EFF & 0.549 & 0.546 & 0.048 & 11.466 & 0.000 \\
\hline
\end{tabular}

control effectiveness. Although control activities has a negative coefficient of -0.921 it remains statistically significant based on it $p$ value of $p=0.000$. It implies that, control activities are exiting but the impact is low while the real effect on internal control is negative. Control environment, information and communication as well as risk assessment are having positive $\mathrm{p}$ values $0.016,0.000$ and 0.000 respectively. The results also informs the decision and sets the criteria for rejecting the null hypothesis. The components of internal control consisting of the five main independents variables in this study, influences the dependent variables thus control effectiveness in the following way: control environment explains $\beta=0.149$, sig $(\mathrm{p})=0.000$ of effectiveness and risk assessment is estimated to change control practices at $\beta=0.549$ and significant at $(\mathrm{p})=0.000$. This outcomes, implies that, the variables are good determinates of effective internal controls in public organizations and can contribute significantly by any unit increase in effectiveness of internal controls. However, internal control monitoring appears insignificant at $\beta=-0.042(\mathrm{p})=0.261$, which is much higher than $0.05 \%$, implying that even with $\beta=-0.042$. Coefficient value, it's supposed real impact on internal control could not immaterial. This is indicated in Figure 5. The total variance caused by the independent variables put together is value of $R^{2}=0.888$. Therefore, it could be said that the models explains a positive relationship between the target variable and the constructs. Also, any management policy or decisions concerning internal control effectiveness can be solidly based on the outcome of Table 5. Subsequently, $\mathrm{H}_{1}, \mathrm{H}_{2}, \mathrm{H}_{4}$, and $\mathrm{H}_{5}$ support the model fitness $\mathrm{R}^{2}=0.888$ at a predictive efficiency suggesting that the null hypotheses be rejected except $\mathrm{H}_{3}$. The criteria of for determining quality prediction is when the $\mathrm{R}^{2}$ value is higher than.35\%, according to Cohen (1988).

\subsection{Path analysis of the structural equation model}

The researcher modeled a structural equation to determine the impact of the constructs on internal control effectiveness when the mediated by information and communication. Information and communication plays an important role in the effectiveness of internal controls such as enhancing and coordinating the linkage between all the elements of controls. Figure 5, when information and communication mediates Risk Assessment, the total effect on internal control effectiveness is positive and significant. Risk Assessment enhances information and communication by $(\beta=0.33)$, while Control Activities enhances information and communication by $(\beta=$ $0.93)$ and Control Environment enhancing information and communication by $(\beta=0.11)$. The total impact of the mediation is $(\beta=0.20)$. Meanwhile, Monitoring directly influences effective controls by $(\beta=0.40)$.

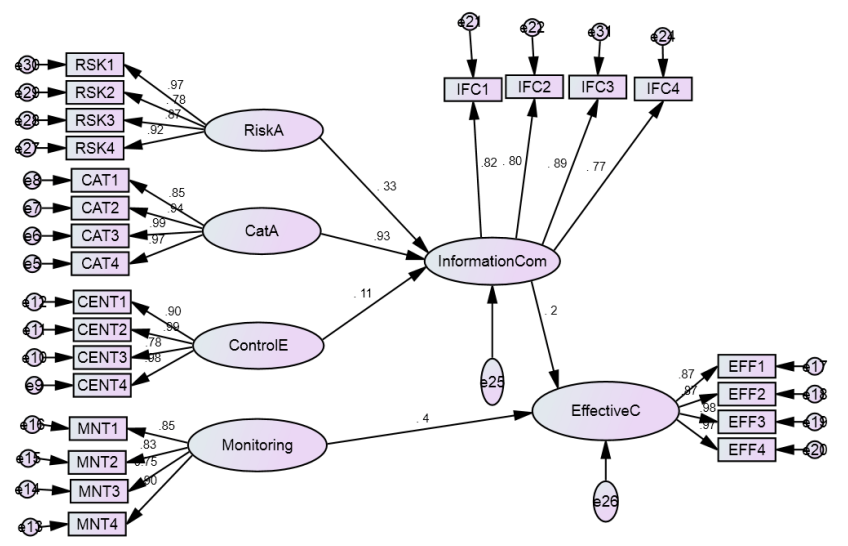

Figure 5 Structural model indicating mediation and path coefficients

The results also shows that the coefficients of the relationship based on direct estimates which also means the degree of impact existing between the variables as they interact. The estimated 
coefficient of Control Activities on information and Communication is $\beta=.928$ and it has a relatively higher mediation impact. (see in Table 6)

Table 6 Direct effects

\begin{tabular}{lc}
\hline Constructs & Coefficients \\
\hline InformationCom <- RiskA & 0.331 \\
InformationCom <- CatA & 0.928 \\
InformationCom <- ControlE & 0.112 \\
EffectiveC <- InformationCom & 0.207 \\
EffectiveC <- Monitoring & 0.401 \\
\hline
\end{tabular}

\subsection{Parameter estimate}

In Table 7, the results shows the significance levels of each construct associating in both direct and indirect relationships. The variance or the relative impact for each construct is significant at 0.000. This significant level is corresponding to positive standard errors for each construct. The relationship between Risk Assessment and information is having a $\mathrm{S} . \mathrm{E}=0.02, \mathrm{CR}=22.091$ and estimated variance of 0.438 which is significant at $\mathrm{p}<0.000$. Apart from significant level the $\mathrm{CR}$ ratio is indication of reliability of the model. Most empirical researchers a satisfactory $\mathrm{CR}$ ration when the value is higher than 1.96. Observing the value in Table 7, control activities (CAT) has a significant impact on information with $\mathrm{S} . \mathrm{E}=0.56, \mathrm{CR}=21.198$, and coefficient estimate of $\beta=0.181$ which is significant $\mathrm{p}<0.000$. Furthermore, the mediation between control environment and information is highly significant at $p<0.000$ and the coefficient of estimate is $\beta=0.129$. The relative impact of information and communication on effectiveness is significant at $\mathrm{p}<0.000$ with $\mathrm{CR}=22.44, \mathrm{~S} . \mathrm{E}=0.044$ and a coefficient estimate of $\beta=0.989$. The result also shows that monitoring significantly influences effective controls at $\mathrm{p}<0.000$ where the coefficient estimate is $\beta=0.056$ at $\mathrm{S} . \mathrm{E}=0.012$ and $\mathrm{CR}$ ratio of 4.711 . The overall evaluation of the result suggest that the effectiveness of internal controls is determined by all the five constructs in both direct and through mediation effect. Further inferential judgments are based on the loadings of measurement items of each construct and their significant levels.

Table 7 Regression weight of controls effectiveness

\begin{tabular}{|c|c|c|c|c|c|c|}
\hline \multicolumn{3}{|c|}{ Parameter Estimates } & \multirow{2}{*}{$\frac{\text { Estimate }}{0.438}$} & \multirow{2}{*}{$\frac{\text { S.E. }}{0.020}$} & \multirow{2}{*}{$\begin{array}{r}\text { C.R. } \\
22.091\end{array}$} & \multirow{2}{*}{$\frac{\mathrm{P}}{* * *}$} \\
\hline InformationCom & $<-$ & RiskA & & & & \\
\hline InformationCom & $<-$ & CatA & 0.181 & 0.056 & 21.198 & $* * *$ \\
\hline InformationCom & $<-$ & ControlE & 0.129 & 0.011 & 11.221 & $* * *$ \\
\hline EffectiveC & $<-$ & InformationCom & 0.989 & 0.044 & 22.441 & $* * *$ \\
\hline EffectiveC & $<-$ & Monitoring & 0.056 & 0.012 & 4.711 & $* * *$ \\
\hline CAT4 & $<-$ & CatA & 0.873 & 0.029 & 29.952 & $* * *$ \\
\hline CAT3 & $<-$ & CatA & 0.806 & 0.026 & 30.916 & $* * *$ \\
\hline CAT2 & $<-$ & CatA & 0.857 & 0.031 & 27.748 & $* * *$ \\
\hline CAT1 & $<-$ & CatA & 1.000 & & & \\
\hline CENT4 & $<-$ & ControlE & 0.956 & 0.025 & 38.210 & $* * *$ \\
\hline CENT3 & $<-$ & ControlE & 0.860 & 0.041 & 21.120 & $* * *$ \\
\hline CENT2 & $<-$ & ControlE & 0.949 & 0.024 & 38.924 & $* * *$ \\
\hline CENT1 & $<-$ & ControlE & 1.000 & & & \\
\hline MNT4 & $<-$ & Monitoring & 1.776 & 0.068 & 26.109 & $* * *$ \\
\hline MNT3 & $<-$ & Monitoring & 1.433 & 0.042 & 34.160 & $* * *$ \\
\hline MNT2 & $<-$ & Monitoring & 1.260 & 0.055 & 22.758 & $* * *$ \\
\hline MNT1 & $<-$ & Monitoring & 1.000 & & & \\
\hline EFF1 & $<-$ & EffectiveC & 1.000 & & & \\
\hline EFF2 & $<-$ & EffectiveC & 1.049 & 0.041 & 25.427 & $* * *$ \\
\hline EFF3 & $<-$ & EffectiveC & 0.734 & 0.022 & 33.688 & $* * *$ \\
\hline EFF4 & $<-$ & EffectiveC & 0.764 & 0.023 & 32.567 & $* * *$ \\
\hline IFC1 & $<-$ & InformationCom & 1.000 & & & \\
\hline IFC2 & $<-$ & InformationCom & 0.752 & 0.027 & 27.719 & $* * *$ \\
\hline IFC3 & $<-$ & InformationCom & 1.066 & 0.037 & 28.591 & $* * *$ \\
\hline IFC4 & $<-$ & InformationCom & 0.949 & 0.033 & 28.699 & $* * *$ \\
\hline RSK4 & $<-$ & RiskA & 0.812 & 0.019 & 41.976 & $* * *$ \\
\hline RSK3 & $<-$ & RiskA & 1.502 & 0.045 & 33.050 & $* * *$ \\
\hline RSK2 & $<-$ & RiskA & 1.147 & 0.014 & 83.807 & $* * *$ \\
\hline RSK1 & $<-$ & RiskA & 1.000 & & & \\
\hline
\end{tabular}

Table 7 shows that effective internal controls that relies on principles such risk assessment, control environment, monitoring, information and communication, and control activities which 
is a good approach for enhancing internal control effectiveness, guiding and empowerment through commitment to programs that enhances efficiency of public organizations. This result also implies that, if individuals must interact through their working environments with strict monitoring it can lead to compliance with control practices even between senior and junior officers before people can comfortably work in a group and encourage delegation of duties.

Total regression estimates shows the variance or the model explanatory power is interpreted based on each individual variable regression weights. It also depend on a robustness check using bootstrapping which produced a model significance of 0.000 . However, from a regression point of view, the pa indicate that the exogenous variables significantly explains behavioral climate using of soft control variables and a single hard control variable. Therefore, the study presents an empirical evidence that soft controls are good determinants of performance of people in an organization.

The regression weights are represented as the indictors of the impact the constructs are having on the dependent variables. This represent the standardized estimates which is also considered the regression coefficients that determines the choice of rejecting or accepting the null hypothesis. The estimates produced positive coefficients implying that the components of control considered in this study would positively influence compliance. Even the covariance indices technically supports the rejection of the null hypothesis and significant at 0.001 level. From the Table 3.6, compliance will be influenced positively by controls activities at $(\beta 0.432)$. Control environment will positively influence effectiveness by ( $\beta .529)$, while control environment will multiply effectiveness by $(\beta$ 0.529). Monitoring is among the highly influential factors, having coefficient regression estimate of $(\beta 0.350)$ and by implication, the independent constructs have a substantial influence and positive relationship with internal control compliance, hence, if enforced in the public sector, there would be a significant impact on performance. Overall, the model has demonstrated that, internal control is a good predictor of performance, hence the theory is relevant and could bring assurance of achieving transparency and efficiency and restore ethical practices in public organizations. This relationship is expressed using the likelihood function $\mathrm{L}(\pi)$, drawn from the Generalized linear models.

Table 8 Regression variances

\begin{tabular}{|c|c|c|c|c|}
\hline & Estimate & S.E. & C.R. & $\mathrm{P}$ \\
\hline CatA & 0.432 & 0.041 & 10.585 & $* * *$ \\
\hline ControlE & 0.529 & 0.045 & 11.640 & $* * *$ \\
\hline Monitoring & 0.350 & 0.033 & 10.723 & $* * *$ \\
\hline RiskA & 0.401 & 0.030 & 13.357 & $* * *$ \\
\hline e25 & 0.011 & 0.002 & 5.942 & $* * *$ \\
\hline e26 & 0.003 & 0.002 & 1.957 & 0.050 \\
\hline e5 & 0.018 & 0.002 & 11.705 & $* * *$ \\
\hline e6 & 0.007 & 0.001 & 8.859 & $* * *$ \\
\hline e7 & 0.040 & 0.003 & 13.132 & $* * *$ \\
\hline e8 & 0.167 & 0.012 & 13.804 & $* * *$ \\
\hline e9 & 0.017 & 0.003 & 6.230 & $* * *$ \\
\hline e10 & 0.254 & 0.018 & 13.840 & $* * *$ \\
\hline e11 & 0.011 & 0.003 & 4.405 & $* * *$ \\
\hline e12 & 0.123 & 0.009 & 13.305 & $* * *$ \\
\hline e13 & 0.273 & 0.019 & 14.116 & $* * *$ \\
\hline e14 & -0.035 & 0.005 & -6.848 & $* * *$ \\
\hline e15 & 0.249 & 0.017 & 14.807 & $* * *$ \\
\hline e16 & 0.130 & 0.009 & 14.665 & $* * *$ \\
\hline e17 & 0.211 & 0.015 & 13.835 & $* * *$ \\
\hline e18 & 0.232 & 0.017 & 13.835 & $* * *$ \\
\hline e19 & 0.016 & 0.001 & 10.843 & $* * *$ \\
\hline e20 & 0.027 & 0.002 & 12.347 & $* * *$ \\
\hline e21 & 0.334 & 0.024 & 14.048 & $* * *$ \\
\hline $\mathrm{e} 22$ & 0.016 & 0.001 & 13.197 & $* * *$ \\
\hline e24 & 0.003 & 0.000 & 7.043 & $* * *$ \\
\hline e27 & 0.045 & 0.003 & 13.971 & $* * *$ \\
\hline $\mathrm{e} 28$ & 0.279 & 0.020 & 14.183 & $* * *$ \\
\hline e29 & -.003 & 0.001 & -1.742 & 0.082 \\
\hline e30 & 0.023 & 0.002 & 11.918 & $* * *$ \\
\hline e31 & 0.007 & 0.001 & 9.572 & $* * *$ \\
\hline
\end{tabular}

In Table 8 Convergent validity determines the significance level of the measurement items of the latent constructs. The measurement items are only considered valid when the score values are statistically significant. In Table 8, the convergent and discriminant value are displayed significant values describing the validity of the constructs. The table shows the Average Variance 
Extracted (AVE) and Construct Reliability which are highly significant. According to leading authors, SEM, AVE CR scores above 0.6 and 0.5 are satisfactory scores to guarantee total validity. It does several analysis as it measures the relationship between constructs and examines the impact on the latent variables on the factor variable. The relationship between the target variable (effectiveness) and the independent constructs are based on the underlined hypothesis linking the latent variables to the observed variable. With the use of factor analysis, we could determine the direction and dimensionality of the data set relative to the influence of the explanatory variables, and also observe outcome and variance relating to each factor. The researcher's judgment, interpretations and inferential analysis are based on a set of criteria proposed by earlier scholars whose findings are still considered relevant assumptions underlining the application of confirmatory factor analysis, regression weights, goodness of fit and many other measuring criteria. The convergent validity could also be verified by computing the Average Variance Extracted (AVE) for every construct. From Table 9 Information has AVE $=0.808, \mathrm{CR}=0.942 ;$ Risk Assessment has $\mathrm{AVE}=0.904, \mathrm{CR}=0.974$. Furthermore, Control Activities has $\mathrm{AVE}=0.891, \mathrm{CR}=0.970$; Monitoring has $\mathrm{AVE}=0.736$ while Effective controls has the minimum AVE $=0.627$. The result shows that the all the constructs have met the convergence validity requirement.

Table 9 Convergent and discriminant validity

\begin{tabular}{|c|c|c|c|c|c|c|c|c|c|c|}
\hline & $\mathrm{CR}$ & AVE & MSV & $\operatorname{Max} \mathrm{R}(\mathrm{H})$ & Inform C & Risk A & Control A & Monitor & Control E & Effective $\mathrm{C}$ \\
\hline InformC & 0.942 & 0.808 & 0.984 & 0.990 & 0.899 & & & & & \\
\hline RiskA & 0.974 & 0.904 & 0.972 & 0.986 & 0.851 & 0.951 & & & & \\
\hline ControlA & 0.970 & 0.891 & 0.972 & 0.985 & 0.905 & 0.986 & 0.944 & & & \\
\hline Monitorin & 0.916 & 0.736 & 0.949 & 0.979 & 0.790 & 0.951 & 0.908 & 0.858 & & \\
\hline ControlE & 0.956 & 0.845 & 0.949 & 0.987 & 0.759 & 0.951 & 0.931 & 0.974 & 0.919 & \\
\hline EffectiveC & 0.867 & 0.627 & 0.984 & 0.929 & 0.992 & 0.772 & 0.841 & 0.739 & 0.693 & 0.792 \\
\hline
\end{tabular}

\subsection{Goodness of fit and performance of the model}

Empirical researchers rely on various model fit indicators to evaluate the model predictive performance in structural equation modelling (SEM), notably the chi-square test and other goodness-of -fit indicators for assessing restricted models to the dataset. Table 10 presents popular fit indicators such as the Root square error of approximation (RMSEA), Pclose, Tucker-Lewis index (TLI), Normed fit index (NFI), the HOELTER Critical N, Comparative fit index(CFI), Goodness of Fit index (GFI) and the AGFI. The soundness of these fit indicators work with different measurements scales, data sample, category of data and specific acceptance criteria of judging a model reliability and goodness [45]. Most empirical researchers only limit their report to RMSEA, CFI, Chi-square, GFI and AGFI [46]. However, this study reports on the model fitness comprehensively using several indicators reported in the Model fit summary output of AMOS and SmartPLS. The result shows that the Chi-square (CMIN/df) also known as the chi-square fit index is derived by dividing the chi-square ratio by the degree of freedom. The resultant value shows whether the model is over dependent on the sample size or otherwise. The criteria for measuring a good fit ranges between 2 and 3 according to McIver and Carmines [47], Silverstein, Brin [48] prescribed 2 or lesser is a good fit, Kline [49], measured good fit by 3, while Lomax and Schumacker [50], insisted on 5 was a good measure of model wellness despite many preferred as smellers ratios as 2 and. However, it agreeable that chai-ratio less that 1 indicates a poor model fit and should not be reported [51]. Going by the above assumption the model chi-square ratio of $\mathrm{x}^{2} / \mathrm{df}=1.5$ is significant enough to pass the model fit.

The Root mean Square Error of Approximation (RMSEA), is also a good measure of model fitness, but many researchers prefer to apply it to a sample size lesser that 400, likewise the CFI, TLI, NFI and AGI. In order to avoid misjudgment of the model fitness, the RMSEA confirms the model fitness by 0.04 as a reliable indicator of a good fit which pass the standard criteria of 0.05 [52] Alternatively, the GFI, TLI, CFI, NFI and AGFI collectively have a fitness criteria between 0 and 1, but arguably empirical researchers often report between 0.90 and 0.95 [53]. It can be inferred that, the model significance of $x^{2}=0.000$ contributed to CPI $=0.93$, TLI $=0.85$, GFI $=0.91$, AGFI $=0.92$ and NFI of 0.88 . However, two indicators could not pass the cutoff score. Hoelter "Critical N" became an acceptable measure goodness fit and hypothesis testing. This test applies to larger sample size of 400 and above, of which most the above fit indicators may tend to produce negative fitness values Hoelter [54], there is no categorical significance value but earlier studies applied 0.05 and 0.01 using AMOS, and that depends on context and subject of study. With a sample size of 460 , the HOAELTER Critical N statistic is 0.01 , exactly what was reported by $\mathrm{Hu}$ and Bentler [55] as a satisfactory fit to reject the null hypothesis. 
Table 10 Model fit indices

\begin{tabular}{lcc}
\hline Fitness Indices & $\begin{array}{c}\text { Standard Fit } \\
\text { \& Criteria }\end{array}$ & Model Result \\
\hline Chi-square, $\chi^{2}$ (CMIN) & $\geq \leq$ & 56.069 \\
Degrees of Freedom (DF) & - & 37.000 \\
$\chi^{2}$ Significance & Model Sig $(\mathrm{p} \leq 0.05)$ & 0.000 \\
$\chi^{2} /$ DF & $<5.00$ & 1.510 \\
Goodness of Fit Index (GFI) & $>0.90$ & 0.910 \\
Adjusted Goodness of Fit Index (AGFI) & $>0.90$ & 0.810 \\
HOELTER N Statistic & $\leq 0.05$ & 0.010 \\
Comparative Fit Index (CFI) & $>0.90$ & 0.930 \\
Tucker-Lewis Index (TLI) & $\geq 0.95$ & 0.850 \\
Normed Fit Index (NFI) & $\geq 0.90$ & 0.880 \\
Root Mean Square Error of Approximation (RMSEA) & $\leq 0.05$ & 0.040 \\
PCLOSE & $\leq 0.06$ & 0.000 \\
\hline
\end{tabular}

Lastly, the P of close fit, also known as Pclose is another test of hypothesis when the RMSEA assumes a correct fit of 0.05 , but such a model must have minimum error specification, hence the name close fitting model [55]. In this case the null hypotheses may be rejected because the Pclose is lesser than the value of the RSMEA. Pclose could be relied on to reject the model significance if the Pclose value is greater than the RSMEA.

\section{Discussion and hypotheses testing}

The empirical significance of this study may not be complete without testing the hypotheses. Each hypotheses has an important role to play to confirm the importance of this research and contribute value to existing knowledge. Starting from Hypothesis $\mathbf{1 a}$, the researcher proposed that, control environment positively enhances effective internal controls. This relationship is strongly established and confirmed that when the management policies are effective they contribute significantly to internal controls.

Additionally, the results also confirms that Hypotheses $\mathbf{1 b}$ : the relationship between control environment and effective control is mediated by information and communication is true. The researcher intend to suggest that the impact control environment on effectiveness can actually be enhanced when management uses the best information and communication channels to in their internal control systems.

The findings also confirms Hypothesis 2a: risk assessment positively enhances internal controls. This hypothesis is measured in a direct relationship and the outcome is positive. The significance of this result also means that when public organizations implement proper internal controls and do a detailed risk assessment the general effectiveness is high. Similarly, the result shows that information and communication also enhances the impact of risk assessment on control effectiveness when mediated. This confirmed by testing Hypothesis $2 \boldsymbol{b}$.

Empirically, the impact of risk assessment, monitoring, controls activities and information and communication equally produced significant impact, except that monitoring and control activities recorded an insignificant coefficients. Irrespective of the coefficients, the study confirms through Hypothesis 3, 4 and 5 the five principles of internal controls are strong determinants.

For the purposes of clarity and future implication, it could be inferred from the weak significance values of control activities and monitoring are as a result weak internal controls policies that supports risk assessment. It also means that in the public sector, critical control activities that are taken after risk assessment might not be implemented, such segregation of duties, separation of functions, transfer, and rotation of employees and even reconciliation of banks accounts with ledgers may not have been done [56]. On the issue of information and communication, the higher $p$ value suggest there is clarity in information, clear instruction and guidance on the part of management to use effective channels of communication to send instructions and get appropriate feedbacks timely enough to inform decisions [35]. Monitoring plays a critical role in enhancing internal controls. If monitoring if weak, other elements may be ineffective, because apart from risk assessment which also identifies certain risks and problems, detailed evaluation of overall internal control efficiency is done by monitoring the results and informing management policy on controls [29]. It is only monitoring that can inform managements about deviations and standards against performance and the overall relevance and quality of the system of controls. Monitoring also compare periodic result, projections to actual results. (see in Table 11)

The t-test produced relatively positive values, to rely on to judge the explanatory power of 
Table 11 Hypotheses Acceptance

\begin{tabular}{l} 
Hypothesis \\
\hline Hypothesis 1a: control environment positively enhances effective internal controls \\
Hypotheses 1b: the relationship between control environment and effective control is mediated by information and communication \\
\hline Hypothesis 2a: risk assessment positively enhances internal controls \\
Hypothesis 2b: the impact of risk assessment on effective control is mediated by information and communication \\
\hline Hypothesis 3a: control activities has a positive impact on internal controls in public sector \\
Hypothesis 3b: the impact of control activities on effectiveness is enhanced by information and communication \\
\hline Hypothesis 4: monitoring significantly enhances control effectiveness \\
\hline Hypothesis 5: information and communication significantly enhances internal control effectiveness \\
\hline
\end{tabular}

the determinants of internal control effectiveness. The model also produced reasonably minimal coefficient errors, and very positive unstandardized coefficients beta. From the perspective of the public sector, it could be implied that internal control effectiveness is based on the five components of internal controls. The most influential constructs are control environment, representing an estimated change that will occur if any decision is taken to strengthen controls based on integrity, positive tone, core values, the organizational philosophy and the organizational structure.

\section{Conclusion}

Internal controls play an important role in every organization, particularly in the public sector. The study's goal is to examine the control policies that determine operational efficiency, compliance with laws, achieving strategic goals, maintaining an ethical environment, and supporting good governance. Based on the feedback received, it is possible to conclude that internal controls are sufficiently effective in public organizations. Managing people's behavior in an organization can be similar to managing bureaucracy to improve service delivery in government organizations. The importance of maintaining adequate internal control in government organizations stems from the fact that government spending accounts for a chunk of a country's economic growth. As a result, in the face of transparency, governance, leadership, and controls, the behavior of those in charge of executing various public expenditures is a major concern. The method of control is determined by a combination of leadership style and posture of those in charge of governance. According to Webber's [57] "Economy of Society," bureaucracy is the best way to keep law and order in a large organization, such as the public sector. It went on to say that the structure of bureaucracy improves process consistency when managing human institutions. This statement defines some features of public controls, such as multiple layers of legislative procedures, hierarchical powers, and excessive protocols, which are often referred to as the "iron cage of control."

New and emerging studies are shaping the style of management control, but major concerns remain with the public sector, where most of the characteristics of bureaucracy are largely visible, such as division of labor based on clearly defined objectives and specific talks, explicitly written formal rules, procedures with structured guidelines for employees to follow, and so on [58]. Others include a long chain of command in the public sector, with decision-making authority delegated to those at the top, and then performance measurement such as productivity, promotion, and reward are based solely on merit [59]. These are clear examples of internal controls that, if not implemented properly, can destroy creativity, knowledge sharing, delegation, diversity, collectiveness, and freedom of expression.

A new approach to management controls focuses on the five principles of internal controls, which guide the board of directors and management in carrying out their oversight responsibilities. A thorough examination of the findings indicates that internal controls are effective, while public organizations ensure that they maintain a fair balance between leadership expectations, employee well-being, and stakeholders [60]. The board reviews policies and approves operational strategies; however, encouraging employee competence will improve sound management practices rather than relying too heavily on resource planning and budgeting, maintaining accounting security and physical controls, and issuing authorizations in accordance with standard policies and procedures to maintain orderliness. This is about the control environment. According to Christensen, Lgreid [61], autocratic leadership does not guarantee effective controls because the influence is not permanent and can also face rebellion fears. On the other hand, culture and ethical values, as well as an individual's social network supported by internal communication, are more likely to shape people's behavior. The findings confirm that if 
culture and ethical values replace excessive bureaucracy, which refers to hard controls, it may address major weaknesses of internal controls such as management overriding and disregarding a well-designed control system in pursuit of their personal interests.

\section{References}

[1] Zarychta, A, Grillos T and Andersson KP. Public Sector Governance Reform and the Motivation of Street-Level Bureaucrats in Developing Countries. Public Administration Review, 2020, 80(1): 75-91. https://doi.org/10.1111/puar.13132

[2] Torfing J, Srensen E and Riseland A. Transforming the public sector into an arena for co-creation: Barriers, drivers, benefits, and ways forward. Administration \& Society, 2019, 51(5): 795-825. https://doi.org/10.1177/0095399716680057

[3] Christl M, Kppl-Turyna M and Kucsera D. Determinants of Public-Sector Efficiency: Decentralization and Fiscal Rules. Kyklos, 2020, 73(2): 253-290. https://doi.org/10.1111/kykl.12224

[4] Alawattage C and Azure JD-C. Behind the World Bank's ringing declarations of "social accountability": Ghana's public financial management reform. Critical perspectives on accounting, 2019.

[5] INTOSAI I. Guidelines for Internal Control Standards for the Public Sector. Jones M.(2008). Dialogus de Scaccario (c. 1179): the first Western book on accounting, 2004.

[6] COSO, COSO Internal Control - Integrated Framework Principles. Committee of Sponsoring Organizations of the Tread way Commission - www.coso.org, 2013.

[7] OECD O. The OECD principles of corporate governance. Contadura y Administracin, 2004(216) https://doi.org/10.22201/fca.24488410e.2005.562

[8] COSO, Internal Control, Integrated Framework: Executive Summary. 1992: Committee of Sponsoring Organizations of the Treadway Commission.

[9] COSO. Improving Organizational Performamnce and Governance How the COSO Framework Can Help 2015. https://www.coso.org/Documents/2014-2-10-COSO-Thought-Paper.pdf

[10] COSO, COSO Enterprise Risk Management - Integrating with Strategy and Performance: Compendium of Examples, J.B. Suzanne Dawson, Editor. 2018, S\&C Public Relations Inc: New York.

[11] Commission, C.o.S.O.o.t.T., COSO Internal control-integrated framework: Guidance on monitoring internal control systems, Volume III: Examples. 2009.

[12] Lartey PY, Kong YS, Bah FBM, et al. Determinants of Internal Control Compliance in Public Organizations; Using Preventive, Detective, Corrective and Directive Controls. International Journal of Public Administration, 2020, 43(8): 711-723. https://doi.org/10.1080/01900692.2019.1645689

[13] Chang YT, Chen HC, Cheng RK, et al. The impact of internal audit attributes on the effectiveness of internal control over operations and compliance. Journal of Contemporary Accounting \& Economics, 2019, 15(1): 1-19. https://doi.org/10.1016/j.jcae.2018.11.002

[14] Kong Y, Lartey, PY, Bah FBM, et al. The Value of Public Sector Risk Management: An Empirical Assessment of Ghana. Administrative Sciences, 2018, 8(3): 40. https://doi.org/10.3390/admsci8030040

[15] Udeh I. Observed effectiveness of the COSO 2013 framework. Journal of Accounting \& Organizational Change, 2019. https://doi.org/10.1108/JAOC-07-2018-0064

[16] Pakurr M, Haddad H, Nagy J, et al. The impact of supply chain integration and internal control on financial performance in the Jordanian banking sector. Sustainability, 2019, 11(5): 1248. https://doi.org/10.3390/su11051248

[17] Pieket Weeserik B and Spruit M. Improving Operational Risk Management Using Business Performance Management Technologies. Sustainability, 2018, 10(3): 640. https://doi.org/10.3390/su10030640

[18] Hanggraeni D, lusarczyk B, Sulung LAK, et al. The Impact of Internal, External and Enterprise Risk Management on the Performance of Micro, Small and Medium Enterprises. Sustainability, 2019, 11(7): 2172 . https://doi.org/10.3390/su11072172

[19] Liu, JY. An internal control system that includes corporate social responsibility for social sustainability in the new era. Sustainability, 2018, 10(10): 3382. https://doi.org/10.3390/su10103382

[20] Ferry L. Managing Organisational Culture for Effective Internal Control: From Practice to Theory. The British Accounting Review, 2011, 43(2): 147-148. https://doi.org/10.1016/j.bar.2011.03.003

[21] Gurd B and Helliar C. Looking for leaders: 'Balancing' innovation, risk and management control systems. The British Accounting Review, 2017, 49(1): 91-102. https://doi.org/10.1016/j.bar.2016.10.008

[22] Organ DW. Leadership: The great man theory revisited. Business Horizons, 1996, 39(3): 1-4. https://doi.org/10.1016/S0007-6813(96)90001-4 
[23] Li X, Zheng CM, Liu G, et al. The effectiveness of internal control and corporate social responsibility: Evidence from Chinese capital market. Sustainability, 2018, 10(11): 4006. https://doi.org/10.3390/su10114006

[24] Bellavite Pellegrini C, Meoli M and Urga G. Money market funds, shadow banking and systemic risk in United Kingdom. Finance Research Letters, 2017, 21: 163-171. https://doi.org/10.1016/j.frl.2017.02.002

[25] Lartey PY, Afriyie S, Santosh RJ, et al. Corporate Governance Issues in the Public Sector: Board Perspective and Peculiarities. Brazilian Journal of Operations \& Production Management, 2020, 17(1): 1-14. https://doi.org/10.14488/BJOPM.2020.001

[26] Demek KC, Raschke RL, Janvrin DJ, et al. Do organizations use a formalized risk management process to address social media risk? International Journal of Accounting Information Systems, 2018, 28: $31-44$. https://doi.org/10.1016/j.accinf.2017.12.004

[27] Lawson BP, Muriel L and Sanders PR. A survey on firms' implementation of COSO's 2013 Internal Control-Integrated Framework. Research in Accounting Regulation, 2017, 29(1): 30-43. https://doi.org/10.1016/j.racreg.2017.04.004

[28] Doyle J, Ge W and McVay S. Determinants of weaknesses in internal control over financial reporting. Journal of Accounting and Economics, 2007, 44(1): 193-223. https://doi.org/10.1016/j.jacceco.2006.10.003

[29] Oussii AA and Taktak NB. The impact of internal audit function characteristics on internal control quality. Managerial Auditing Journal, 2018. https://doi.org/10.1108/MAJ-06-2017-1579

[30] Kaya . Perspectives on Internal Control and Enterprise Risk Management. in Eurasian Business Perspectives, 2018, 379-389. https://doi.org/10.1007/978-3-319-67913-6_26

[31] Woods M, Linsley P and Maffei M. Accounting and Risk Special Issue: Editorial. The British Accounting Review, 2017, 49(1): 1-3. https://doi.org/10.1016/j.bar.2016.11.002

[32] Chen H, Yang DG, Zhang XM, et al. The Moderating Role of Internal Control in Tax Avoidance: Evidence from a COSO-Based Internal Control Index in China. The Journal of the American Taxation Association, 2020, 42(1): 23-55. https://doi.org/10.2308/atax-52408

[33] Prajogo D, Toy J, Bhattacharya A, et al. The relationships between information management, process management and operational performance: Internal and external contexts. International Journal of Production Economics, 2018, 199: 95-103. https://doi.org/10.1016/j.ijpe.2018.02.019

[34] Apergis N, Fafaliou I and Stefanitsis M. Asymmetric information and employment: evidence from the U.S. banking sector. The Journal of Economic Asymmetries, 2016, 14: 199-210. https://doi.org/10.1016/j.jeca.2016.09.001

[35] Johanson JE. Internal Strategic Scanning, in Strategy Formation and Policy Making in Government. 2019, 121-142. https://doi.org/10.1007/978-3-030-03439-9_6

[36] Bolland MJ, Gamble GD, Avenell A, et al. Rounding, but not randomization method, non-normality, or correlation, affected baseline P-value distributions in randomized trials. Journal of Clinical Epidemiology, 2019, 110: 50-62. https://doi.org/10.1016/j.jclinepi.2019.03.001

[37] Hair JF, Risher JJ, Sarstedt M, et al. When to use and how to report the results of PLS-SEM. European Business Review, 2019, 31(1): 2-24. https://doi.org/10.1108/EBR-11-2018-0203

[38] Nedyalkova P. Presentation of the Dependence Between the Chosen Internal Audit Approach and the Methods for Assessing the Quality of the Internal Audit in the Public Sector, in Quality of Internal Auditing in the Public Sector, 2020, 105-114. https://doi.org/10.1007/978-3-030-29329-1_8

[39] Shmueli G and Koppius OR. Predictive analytics in information systems research. MIS quarterly, 2011, 553-572. https://doi.org/10.2307/23042796

[40] Sarstedt M, Ringle CM, Henseler J, et al. On the emancipation of PLS-SEM: A commentary on Rigdon (2012). Long range planning, 2014. 47(3): 154-160. https://doi.org/10.1016/j.lrp.2014.02.007

[41] Henseler J, Ringle CM and Sinkovics RR. The use of partial least squares path modeling in international marketing, in New challenges to international marketing. 2009, Emerald Group Publishing Limited. 277-319. https://doi.org/10.1108/S1474-7979(2009)0000020014

[42] Raithel S, Sarstedt M, Scharf S, et al. On the value relevance of customer satisfaction. Multiple drivers and multiple markets. Journal of the Academy of Marketing Science, 2012, 40(4): 509-525. https://doi.org/10.1007/s11747-011-0247-4

[43] Sekaran U and Bougie R. Theoretical framework in theoretical framework and hypothesis development. Research methods for business: A skill building approach, 2010, 80. 
[44] Fornell C and Larcker DF. Structural equation models with unobservable variables and measurement error: Algebra and statistics. 1981, SAGE Publications Sage CA: Los Angeles, CA. https://doi.org/10.2307/3150980

[45] Bentler PM. Comparative fit indexes in structural models. Psychological bulletin, 1990, 107(2): 238. https://doi.org/10.1037/0033-2909.107.2.238

[46] Schumacker RE. Interaction and nonlinear effects in structural equation modeling. 2017: Routledge. https://doi.org/10.4324/9781315092614

[47] McIver J and Carmines EG. Unidimensional scaling. 1981: Sage. https://doi.org/10.4135/9781412986441

[48] Silverstein C, Brin S, Motwani R, et al. Scalable techniques for mining causal structures. Data Mining and Knowledge Discovery, 2000, 4(2-3): 163-192. https://doi.org/10.1023/A:1009891813863

[49] Kline RB. Structural equation modeling. 1998, New York: Guilford Press.

[50] Lomax RG and Schumacker RE. A beginner's guide to structural equation modeling. 2004: psychology press.

[51] Paswan AK and Wittmann CM. Knowledge management and franchise systems. Industrial Marketing Management, 2009, 38(2): 173-180. https://doi.org/10.1016/j.indmarman.2008.12.005

[52] Steiger JH. Structural model evaluation and modification: An interval estimation approach. Multivariate behavioral research, 1990, 25(2): 173-180 https://doi.org/10.1207/s15327906mbr2502_4

[53] Jreskog KG. Analysis of covariance structures. in Multivariate analysis-III, 1973, 263-285. https://doi.org/10.1016/B978-0-12-426653-7.50024-7

[54] Hoelter JW. The analysis of covariance structures: Goodness-of-fit indices. Sociological Methods \& Research, 1983, 11(3): 325-344. https://doi.org/10.1177/0049124183011003003

[55] Hu LT and Bentler PM. Evaluating model fit, 1995.

[56] Lin YC. The consequences of audit committee quality. Managerial Auditing Journal, 2018. https://doi.org/10.1108/MAJ-03-2016-1350

[57] Webber M. Economy and society. New York: Bedminster, 1992.

[58] Lisic LL, Myers LA, Seidel TA, et al. Does audit committee accounting expertise help to promote audit quality? Evidence from auditor reporting of internal control weaknesses. Contemporary Accounting Research, 2019, 36(4): 2521-2553. https://doi.org/10.1111/1911-3846.12517

[59] Falkenberg L and Herremans I. Ethical behaviours in organizations: directed by the formal or informal systems? Journal of business Ethics, 1995, 14(2): 133-143. https://doi.org/10.1007/BF00872018

[60] Cucari NS. Esposito De Falco and Orlando B. Diversity of board of directors and environmental social governance: Evidence from Italian listed companies. Corporate Social Responsibility and Environmental Management, 2018, 25(3): 250-266. https://doi.org/10.1002/csr.1452

[61] Christensen T, Lgreid P and Rovik KA. Organization theory and the public sector: Instrument, culture and myth. 2020: Routledge. https://doi.org/10.4324/9780367855772 